Cardio Vascular

and Interventional

Radiology
(C) Springer Science+Business Media, Inc. 2006 Published Online: 24 February 2006
Cardiovasc Intervent Radiol (2006) 29:928 DOI: $10.1007 / \mathrm{s} 00270-005-0231-9$

\section{Arterial Embolization of Unresectable Hepatocellular Carcinoma with Use of Microspheres, Lipiodol, and Cyanoacrylate}

The photographs in the article by Dr. Rand et al. [1] raise several problems. In their Fig. 5C hepatic arteriography after embolization using Glubran, lipiodol, and Embospheres reveals an extrahepatic arterial supply via the epicholedochal plexus with faint residual stains. These extrahepatic collaterals are commonly seen after proximal embolization and make repeated embolization for recurrent tumors in the future extremely difficult [2]. Of course, if the tumor is completely killed by the first peripheral embolization using Embospheres this does not matter. However, most hepatocellular carcinomas will recur at the same site or in another segment in the liver. Thus proximal embolization including the proper hepatic artery shown in the image may induce extrahepatic collaterals including the inferior phrenic artery [2], internal mammary artery [3], intercostal artery [4], renal capsular artery [5], or the omental branches [6], in addition to the epicholedochal plexus [2]. As the authors mentioned in the Discussion, peripheral targeted occlusion of tumor vessels by small particles might induce a more permanent occlusion with a longer steady state. I therefore think that additional proximal embolization using lipiodol-NBCA may not be necessary or should be minimal to the intrahepatic artery shown in Rand et al.'s Fig. 4G [1] when the tumor stain disappeared after distal embolization using Embospheres. In relation to extrahepatic collaterals and tumor viability after embolization, a dynamic contrast-enhanced study using multidetector raw CT (MDCT) may be required. The minor peripheral revascularization (Fig. $4 \mathrm{E})$ or the disappearance of revascularization after the second embolization (Fig. 4H) mentioned by Rand et al. in their legend to Fig. 4 should be demonstrated by a dynamic series, and CT angiography using state-of-the-art MD-CT may visualize the extrahepatic collaterals [7] that are important for reinterventions.
Jun Koizumi

Department of Diagnostic Radiology

School of Medicine

Tokai University Bohseidai

Isehara City, Kanagawa Prefecture 259-1193, Japan

\section{References}

1. Rand T, Loewe C, Schoder M, Schmook MT, Peck-Radosavljevic M, Kettenbach J, Wolf F, Schneider B, Lammer J (2005) Arterial embolization of unresectable hepatocellular carcinoma with use of microspheres, lipiodol, and cyanoacrylate. Cardiovasc Intervent Radiol 28:313-318

2. Iwata $\mathrm{Y}$, Endo J, Saito T, Iwata T, Matsuyama S, Tanaka Y, Otani Y, Tsukui S, Goto K, Ikeuchi S (1996) Hepatic embolization through extrahepatic collateral pathways after hepatic arterial embolization for the hepatocellular carcinoma. Tokai J Exp Clin Med 21:177-183

3. Okazaki M, Higashihara H, Nozaki Y (1995) Collateral transcatheter chemoembolization for the treatment of hepatocellular carcinoma. J Jpn Angio Interv Radiol 10:273-278

4. Park SI, Lee do Y, Won JY, Lee JT (2003) Extrahepatic collateral supply of hepatocellular carcinoma by the intercostal arteries. J Vasc Interv Radiol 14:461-468

5. Kodama Y, Shimizu T, Endo H, Hige S, Kamishima T, Holland GA, Miyamoto N, Miyasaka K (2002) Spontaneous rupture of hepatocellular carcinoma supplied by the right renal capsular artery treated by transcatheter arterial embolization. Cardiovasc Intervent Radiol 25:137-140

6. Won JY, Lee do Y, Lee JT, Park SI, Kim MJ, Yoo HS, Suh SH, Park SJ (2003) Supplemental transcatheter arterial chemoembolization through a collateral omental artery: Treatment for hepatocellular carcinoma. Cardiovasc Intervent Radiol 26:136-140

7. Gokan T, Hashimoto T, Matsui S, Kushihashi T, Nobusawa H, Munechika H (2001) Helical CT demonstration of dilated right inferior phrenic arteries as extrahepatic collateral arteries of hepatocellular carcinomas. J Comput Assist Tomogr 25:68-73 